\title{
MEDIOS Y CONSECUENCIAS NECESARIAS. OBSERVACIONES ACERCA DE LA RESPONSABILIDAD PENAL Y LA DOCTRINA DEL DOBLE EFECTO
}

\author{
María Laura Manrique \\ Consejo Nacional de Investigaciones Científicas y Técnicas \\ (CONICET-Argentina) \\ laura.manrique@upf.edu
}

\begin{abstract}
RESUMEN: Este trabajo insiste en la utilidad de la distinción entre medios y consecuencias en la atribución de responsabilidad penal. La estrategia argumental se basa en algunas de las principales intuiciones de la doctrina del doble efecto. En particular, se analiza el modo en que esta doctrina moral traza la diferencia entre daño instrumental y daño incidental. Dado que en la filosofía moral contemporánea se ha criticado severamente esa distinción, se elabora una respuesta a esas críticas. Finalmente, se subraya no sólo en qué sentido es diferente intentar y prever un daño sino también por qué los daños instrumentales cuentan también como daños intentados por el agente.
\end{abstract}

PALABRAS CLAVE: acción intencional, necesidad práctica, daño instrumental, daño incidental, dolo

SUMMARY: The main objective of this paper is to analyze the distinction between means and consequences and to stress its relevance for understanding the attribution of criminal responsibility. Some arguments borrowed from the doctrine of double effect provide the conceptual context for justifying that instrumental and incidental harm must receive different punishment. However, such a distinction has been fiercely criticized in contemporary moral philosophy. For this reason, in order to defend the doctrine of double effect, this paper underlines not only the moral relevance of the distinction between intention and foresight, but it also claims that instrumental harm —unlike the incidental harm — counts as an intended one.

KEY WORDS: intentional action, practical necessity, instrumental harm, incidental harm, dolus

\section{Introducción}

Una de las principales discrepancias en filosofía de la acción gira en torno de la naturaleza causal o conceptual de la relación entre acción y resultado o, de manera más precisa, entre las razones del agente, su conducta y los cambios que ella provoca. Mientras que, en general, filósofos de orientación wittgensteniana (e.g., Anscombe, von Wright, etc.) consideran que esa conexión es de índole conceptual, otros filósofos (Davidson, Goldman, etc.) sostienen que las razones causan las acciones de los agentes. Más allá de esta profunda discrepancia filosófica, existe un acuerdo básico acerca de la causalidad como nexo 
que conecta medios, resultados y consecuencias de las acciones. Así, con independencia de los desacuerdos acerca de la naturaleza de la acción podemos asumir que las relaciones entre el resultado de aquello que el agente hace (i.e., objeto de intención), los medios indispensables que pone en marcha para conseguir sus objetivos y las consecuencias generadas por su conducta pueden ser explicadas a la luz de sus conexiones causales.

Estas conexiones causales entre (i) medios y resultados y (ii) resultados y consecuencias son de enorme relevancia para la atribución de responsabilidad. Así, doctrinas morales como el doble efecto admiten que está prohibido intentar causar un mal como fin de nuestras acciones, i.e., impide que nuestras acciones se guíen por objetos de intención disvaliosos. De igual manera, esta doctrina prohíbe causar un daño como medio para conseguir fines loables (daño instrumental). Por el contrario, la doctrina del doble efecto insiste en la posibilidad y relevancia de la distinción entre el resultado disvalioso intentado y las consecuencias dañinas meramente prevista por el agente (daño incidental). En otras palabras, la doctrina del doble efecto sostiene la asimetría en la evaluación de los daños instrumentales y los daños incidentales. Esta doctrina ha sido objeto de importantes críticas. ${ }^{1}$ Precisamente, una de las críticas contemporáneas más importantes se refiere a la diferente valoración de los daños incidentales e instrumentales. Esta crítica se apoya en razones que guardan una interesante semejanza con las ideas de la dogmática penal. Aunque existe un acuerdo sustancial en la justificación del reproche por resultados disvaliosos que el agente directamente intenta producir (es decir, acerca del llamado "dolo directo"), los defensores de la doctrina del doble efecto diferencian entre los medios necesarios y las consecuencias necesarias meramente previstas, en tanto que los críticos de la doctrina y los cultores de la dogmática penal tienden a rechazar esa diferencia o a negar su relevancia normativa. Así, por ejemplo, para la dogmática penal, el daño previsto por el agente sea como fin, medio o consecuencia queda abarcado en diferentes formas de dolo. En particular, mediante el llamado "dolo directo de segundo grado", "dolo de consecuencias necesarias" o "dolo indirecto" se reprochan los daños que se causan como medio y también como consecuencia necesaria de la acción, aun cuando ese daño no fuese directamente querido por

\footnotetext{
${ }^{1}$ Por ejemplo, los críticos del doble efecto señalan que la distinción entre resultados intentados y consecuencias previstas no es admisible por razones conceptuales (problema de la cercanía), o por razones morales (problema de la relevancia). En otro trabajo he analizado estos problemas clásicos (Manrique 2007, pp. 415-434).
} 
el agente. ${ }^{2}$ En otras palabras, la dogmática penal acepta una simetría en la evaluación de los daños incidentales e instrumentales. Por consiguiente, en la medida en que la responsabilidad penal tiene que fundamentarse en razones morales, las intuiciones subyacentes en el dolo indirecto son en principio incompatibles con las que apoyan la doctrina del doble efecto (Mackie 2000, p. 232; González Lagier 2001, pp. 27 y ss.). ${ }^{3}$

Mi principal propósito es ofrecer razones que puedan disolver ese conflicto de intuiciones. Mi argumentación se proyectará a lo largo de dos dimensiones diferentes. Por una parte, enfrentaré la crítica a la doctrina del doble efecto y subrayaré la diferencia entre daño incidental y daño instrumental. Por otra parte, sostendré que si se aceptan esas diferencias entre medios y consecuencias necesarias, entonces existe un argumento de peso para revisar el alcance que los dogmáticos atribuyen al dolo indirecto.

Por su estructura, este trabajo se divide en tres partes. En la primera, expondré esquemáticamente el concepto de dolo indirecto. En la segunda parte, analizaré la doctrina del doble efecto en cuanto doctrina que defiende la diferencia entre medios y consecuencias necesarias y reconstruiré una de las críticas más importantes a esa diferencia. ${ }^{4}$ Finalmente, presentaré una respuesta a esta crítica y mostraré las implicaciones de esa respuesta en relación con la atribución de responsabilidad penal a título de dolo indirecto. ${ }^{5}$

${ }^{2}$ Por razones de simplicidad, en adelante, para referirme a estas situaciones utilizaré la expresión — un tanto pasada de moda — "dolo indirecto". En la dogmática contemporánea, sin embargo, es usual referirse a esta figura como "dolo directo de segundo grado".

${ }^{3}$ Sin embargo, esta dependencia del derecho penal frente a las razones morales no significa que todo lo que se desaprueba moralmente también deba ser jurídicamente reprochado.

${ }^{4}$ Aunque imprescindible para justificar la doctrina del doble efecto, la diferencia entre medios y consecuencias necesarias no ha sido estudiada con gran cuidado. Las excepciones contemporáneas a esta falta de cuidado pueden verse en: McIntyre 2001, pp. 219-255; Spector 1997, pp. 93-110; Lyons 2005, pp. 469-563; Scanlon 2008.

${ }^{5}$ El marco teórico de este análisis está definido en diferentes trabajos de Georg Henrik von Wright acerca de de la acción humana y su explicación teleológica. De manera rudimentaria, la idea central de este autor es que la conexión que hay entre la acción y su resultado es intrínseca o conceptual, y a su vez, la conexión que posee la acción con los medios y las consecuencias de un agente es extrínseca o causal. Dado que mi preocupación principal en este trabajo se refiere las consecuencias de la conducta de los agentes y los medios que ellos emplean para conseguir sus propósitos, las conclusiones que defenderé en este trabajo son en gran medida independientes de los compromisos específicos acerca de la naturaleza causal o con- 


\section{Medios necesarios, consecuencias y dolo indirecto}

En los derechos continentales y sus respectivas dogmáticas jurídicas, la atribución de responsabilidad penal se divide en dos grandes clases: dolo e imprudencia. Aunque los teóricos han reconstruido diversas clases de dolo (i.e., dolo directo, dolo de consecuencias necesarias, dolo eventual), todas esas figuras conllevan la atribución más severa de responsabilidad. En otras palabras, los reproches a título de dolo son más graves que los reproches por conductas imprudentes y ello corresponde a intuiciones morales ordinarias ampliamente compartidas (véase, por ejemplo, Sancinetti 2005). Así, hay una amplia coincidencia en que no merece el mismo reproche una madre que - deliberadamente - ahoga a su hijo recién nacido que otra madre que, por un descuido, deja que su hijo recién nacido se ahogue.

La explicación tradicional del dolo se realiza en términos de la voluntad del agente y su conocimiento de las consecuencias. ${ }^{6}$ Así, para las doctrinas dogmáticas clásicas, el dolo se vinculaba con aquellas cosas que el agente quiere (intenta) realizar y, por esa razón, normalmente la responsabilidad por el intento fallido de cometer un delito (tentativa) ocupa un lugar intermedio entre el reproche por el delito cometido con dolo y el delito cometido de manera imprudente. En el dolo directo, el reproche se dirige a un agente que tiene por objeto de intención (i.e., persigue como resultado de su acción) un estado de cosas disvalioso. Pero, en otras formas dolosas el agente no busca directamente ese resultado, aunque sabe que los medios que emplea o las consecuencias de su conducta ocasionarán necesariamente (dolo indirecto) o probablemente (dolo eventual) un daño.

El reproche a título de imprudencia abarca situaciones en las que el agente no quiso directamente el resultado disvalioso, pero debería haber cumplido con determinadas normas de cuidado y evitar la consecuencia dañina. Esta figura también suele dividirse en dos clases, la imprudencia consciente y la imprudencia inconsciente, según el agente haya advertido o no los riesgos de ocasionar un daño al realizar su conducta. En otras palabras, tanto el dolo como la imprudencia son

ceptual de la relación entre razones y acciones. Véanse, por ejemplo, von Wright 1979a, von Wright 1979b, y von Wright 1983, pp. 100-129.

${ }^{6}$ En la dogmática contemporánea es ardua la discusión sobre cuáles son los elementos que componen esta figura. No hay acuerdo generalizado en torno a si el dolo debería definirse como conocer y querer la realización de un hecho típico, o sólo en relación con elementos epistémicos, i.e., conocimiento. (Véase, por ejemplo, Ragués 1999.) 
familias conceptuales complejas y, aunque es intuitivo reprochar de diferente manera los delitos dolosos y los imprudentes, no siempre resulta claro que los fundamentos que justifican la distinción puedan aplicarse a todos los casos que la dogmática clasifica como dolo e imprudencia. En particular, como he señalado en la introducción, es preciso revisar el alcance del denominado "dolo indirecto" o "dolo de consecuencias necesarias", porque impide apreciar diferencias relevantes en la evaluación de los daños incidentales e instrumentales (Ragués 1999, p. 46). ${ }^{7}$

La característica distintiva del dolo indirecto es que (i) abarca situaciones en que el agente no pretende conseguir un determinado resultado, pero (ii) sabe que su conducta está conectada necesariamente con una consecuencia disvaliosa. Roxin, refiriéndose a esta clase de dolo, afirma:

[É]ste abarca las consecuencias o circunstancias cuya realización no es intencionada, pero de cuya producción o concurrencia con seguridad se percata el sujeto, ocasionándolas conscientemente. [...] [R]epresenta un "querer" la realización del tipo, aun cuando el resultado sea desagradable para el sujeto. "Las consecuencias de la acción que se reconocen como necesarias son asumidas en su voluntad por el agente, aun cuando no tenga en absoluto interés en esas consecuencias." (Roxin 1997, pp. 423-424)

El llamado "Caso Thomas" se suele emplear como ejemplo de esta figura. Thomas había colocado una bomba en un barco para cobrar el seguro del mismo, sabiendo que con el estallido de la bomba necesariamente morirían la tripulación y los pasajeros. ${ }^{8}$ La intuición que subyace a la reconstrucción del caso Thomas como dolo indirecto

${ }^{7}$ A diferencia de otras figuras en la teoría del delito (e.g., dolo eventual), el dolo indirecto no ha generado gran discusión en la dogmática penal. O, mejor dicho, aunque se ha discutido si el dolo indirecto posee un elemento volitivo o es sólo conocimiento de las consecuencias necesarias, no se ha discutido acerca de las razones o fundamentos para establecer que las conductas que caen bajo esta figura son genuinamente dolosas. La ausencia de discusión podría obedecer a que tenemos una intuición muy fuerte del modo en que estos casos deben resolverse, y a su vez porque las fronteras de esta figura (el dolo directo de primer grado y el dolo eventual) siguen resolviendo los casos con la misma gravedad que el dolo indirecto.

${ }^{8}$ El desarrollo de los acontecimientos en el "caso Thomas" fue bastante diferente de lo que el autor había previsto ya que el tonel con dinamita que Thomas había preparado como explosivo detonó en el muelle mientras era manipulado por los estibadores. Como consecuencia de ello fallecieron 59 personas, 24 desaparecieron y otras 50 quedaron heridas. (Para una reconstrucción de este caso, véanse: Zaffaroni, Alagia y Slokar 2002, p. 524, y Jescheck 1993, p. 269.) 
es que el propietario del barco indirectamente persigue el resultado disvalioso en la medida en que también pretende conseguir su objeto de intención. En otras palabras, mientras delibera, el agente advierte que su acción tendrá necesariamente como consecuencia la muerte de la tripulación y los pasajeros.

Es importante destacar que aun cuando los dogmáticos casi invariablemente asocian al dolo indirecto con las consecuencias necesarias de la conducta de un agente, no siempre resulta claro a qué se refieren con esa conexión. Al respecto, Sancinetti señala:

\begin{abstract}
¿Por qué se le llama, entonces, dolo de "consecuencias necesarias", al que se refiere a una consecuencia que - como la muerte de la tripulación del caso Thomas-, no tiene por qué ocurrir necesariamente? Sólo porque, si se realiza el plan del autor tal cual está previsto, entonces, se producirá la consecuencia necesariamente. Es decir, que lo necesario es la conexión de medio a fin en la que un resultado se halla respecto del otro. $(2005$, p. 147)
\end{abstract}

En el mismo sentido, Zaffaroni, Slokar y Alagia (2002, p. 523) afirman que en el dolo indirecto el resultado "es una consecuencia necesaria de los medios elegidos, que deben ser abarcados por la voluntad tanto como el fin mismo". A su vez, Ricardo Núñez amplía el alcance de esta figura, incorporando también las consecuencias necesarias de los resultados de la acción. En su opinión, aunque en casos de dolo indirecto el agente no desea el fin, el resultado dañoso

[s]e le presenta como algo que, aunque no deseado, está necesariamente ligado a lo querido directamente por él mismo. Esos efectos necesariamente ligados a lo querido directamente por el autor son: a) los medios para la realización del fin deseado [...], b) los obstáculos superados para lograr el fin deseado [...], c) las consecuencias necesarias de la ejecución del fin deseado [...]. (Núñez 1965, pp. 57-58)

Más allá del acierto (o desacierto) de ejemplificar el dolo indirecto mediante el caso Thomas, ${ }^{9}$ es relevante señalar que en este caso las consecuencias disvaliosas no están causalmente conectadas con

${ }^{9}$ Es digno de mención que aun cuando la figura del dolo indirecto ha sido comentada unánimemente por los autores de derecho penal, los ejemplos académicos son escasos. Además, vale la pena señalar que incluso cuando normalmente se menciona el caso Thomas como un ejemplo de dolo indirecto, es frecuente que los autores critiquen esa solución y establezcan la responsabilidad de Thomas a través de otras figuras dogmáticas, e.g., aberratio ictus. 
aquello que el agente intenta conseguir directamente (i.e., el objeto de intención). ${ }^{10}$ En otras palabras, la muerte de los pasajeros y la tripulación no son causalmente necesarias ni suficientes para cobrar el seguro. Esas muertes son consecuencias necesarias del medio necesario (detonar un explosivo) para hundir el buque y cobrar el seguro (objeto de intención). Dado que esas consecuencias necesarias del medio necesario no están causalmente conectadas con el objeto de intención, es preciso explicar en qué sentido ellas son genuinamente dolosas. Una respuesta simple y directa sería que ellas también son queridas por el agente. Ésta parece ser la solución propuesta por Zaffaroni, Slokar y Alagia (2002, p. 523) cuando señalan que "de la incorporación del medio a la voluntad se desprende que esa consecuencia necesaria es también directamente querida". Sin embargo, parece una falacia inferir que esas consecuencias son queridas $-\mathrm{y}$ no meramente previstas - por el solo hecho de que están conectadas con el medio empleado. Por supuesto, nada impide que esas consecuencias sean efectivamente queridas por el agente, pero hace falta un criterio independiente de su conexión con los medios para garantizar la presencia de esa actitud volitiva.

En las próximas secciones sostendré que un análisis más cuidadoso de la estructura de la acción y las distintas clases de conexiones necesarias permite destacar algunas diferencias relevantes en las situaciones englobadas tradicionalmente en la categoría de dolo indirecto. Estas distinciones, sin embargo, no constituyen razones para señalar que todas las instancias de dolo indirecto deban resolverse de forma diferente del modo en que lo hace la dogmática penal. Más bien, entender el dolo indirecto del modo que propongo explica de qué manera esta figura se conecta con aquello que el agente hace. En particular, subrayaré que los medios necesarios forman parte de aquello que el agente intenta y, por esa razón, merece el reproche más grave. Por el contrario, otras consecuencias necesarias de su conducta no están conectadas de esa manera específica con su acción y, por ello, pueden merecer un reproche diferente.

El argumento que usaré en el análisis del dolo indirecto requiere una clara distinción entre daño incidental y daño instrumental. Por

${ }^{10}$ Lo mismo ocurre en otro de los ejemplos paradigmáticamente empleados para ejemplificar el dolo indirecto. Así, también es usual mencionar el caso del que, para matar a su enemigo, hace estallar una bomba en su avión ocasionando la muerte de todos los que van abordo. O quien, para matar al presidente, hace estallar a la comitiva ocasionando también la muerte de los escoltas. En ninguno de estos dos casos, la muerte del enemigo o del presidente causa la muerte de los otros pasajeros o de los escoltas. 
esa razón, la doctrina del doble efecto ofrece un buen punto de partida para revisar los fundamentos del dolo indirecto.

\section{Medios y consecuencias en la doctrina del doble efecto}

La doctrina del doble efecto (en adelante "DDE") se menciona usualmente para justificar casos como la extracción de un útero canceroso a una mujer embarazada (buen efecto) previendo el mal efecto de que el feto morirá como consecuencia de la operación (histerectomía); pero no justifica casos como el del aplastamiento del cráneo de un feto para salvar la vida de la madre (craneotomía). Permite, asimismo, la conducta del médico que administra un sedante a un paciente con una enfermedad terminal y dolorosa previendo que ese medicamento acortará su vida (sedación terminal). Pero la DDE no permite que un médico inyecte una sustancia mortal a un paciente terminal para acabar con su vida y de esa forma poner punto final a su sufrimiento (eutanasia). Otro caso paradigmático de esta doctrina es el intento de justificar la conducta de aquel bombardero que pretende destruir las armas del enemigo, sabiendo que morirá cierta cantidad de personas como consecuencia del bombardeo (bombardero estratégico). Sin embargo, la DDE prohíbe la conducta de quien pretende matar mediante una bomba a la misma cantidad de personas para atemorizar a su rival y así ganar la guerra (bombardero terrorista).

La justificación de estas distinciones es el núcleo del debate sobre la doctrina del doble efecto. Aunque es abundante la discusión acerca de cuáles son las condiciones en las que se aplica esa doctrina, hay acuerdo en que su pilar es la insistencia en la relevancia moral de la distinción entre, por una parte, intentar algo (como fin o como medio) y, por otra parte, prever que determinada consecuencia ocurrirá. En palabras de Horacio Spector (1997, p. 94):

La doctrina del doble efecto traza una distinción entre los fines buscados y los medios elegidos, por un lado, y los efectos colaterales o indirectos, por el otro. En tanto que a veces puede ser moralmente permisible producir un daño como efecto colateral siempre y cuando el objetivo buscado sea suficientemente valioso - dice la doctrina-, nunca es permisible producir un daño como medio (por supuesto, tampoco como fin), incluso si es un medio necesario para alcanzar un fin muy valioso.

Esto significa que un partidario de la DDE debe sostener dos ideas. En primer lugar: es diferente ocasionar un daño como fin que prever que ese mismo daño ocurra como consecuencia; y, en segundo: 
es diferente un daño instrumental que un daño incidental. Dejando de lado los problemas generales subyacentes a la distinción entre intentar y prever, aquí sólo me centraré en la diferencia entre medios necesarios y consecuencias necesarias. Incluso aunque fuese correcto distinguir entre intentar (provocar) un daño como fin y prever que ese mismo daño se produzca como consecuencia, si la distinción entre daño instrumental y daño incidental no pudiese realizarse, ello representaría el colapso de la doctrina del doble efecto. Esto sería así porque (i) o bien la doctrina tendría que permitir medios dañinos para conseguir un buen fin, en cuyo caso no sería más que una versión del consecuencialismo; (ii) o bien tendría que prohibir ocasionar un mal como medio al igual que reprochar una consecuencia dañina prevista y, en este caso, no podría mostrar qué diferencia relevante existe entre los casos que le interesa resolver, e.g., histerectomía frente a craneotomía, bombardero terrorista frente a bombardero estratégico, etcétera.

Gran parte del debate contemporáneo sobre la DDE se ha centrado en la prohibición de los daños instrumentales. Aunque esa prohibición parece un componente necesario de una doctrina moral plausible, existe una sofisticada discusión acerca de la plausibilidad de introducir excepciones. ${ }^{11}$ Dado que la doctrina del doble efecto asume una absoluta prohibición del daño instrumental, una forma específica de crítica a esa doctrina se basa en identificar excepciones a esa prohibición. Por ejemplo, Mackie se pregunta por qué deberíamos mantener el absolutismo moral acerca de los medios utilizados. Aunque asume que la distinción entre medio y consecuencias es posible de realizar, para él la distinción es demasiado fina y excesivamente artificial como para generar consecuencias tan relevantes en la práctica. El absolutismo debería ser "casi" absolutista en relación con los medios. (Mackie 2000, p. 190). Mackie afirma:

El hecho de poner gran énfasis en tan artificiales distinciones no es meramente inverosímil, es también moralmente corrupto. La propia Anscombe ha dicho que, mientras que el rechazo del principio del doble efecto ha significado la corrupción del pensamiento moral no católico,

${ }^{11}$ Así, en cierta medida, la abundante literatura sobre el problema del tranvía (Trolley Case) gira en torno de la admisibilidad de estas excepciones a la prohibición de daño instrumental. Al respecto, véase Otsuka 2008, pp. 107-110. Otsuka señala que no deben darse excepciones al principio de que está mal ocasionar un daño como medio y qué casos utilizados como contraejemplos de la doctrina del doble efecto (como el llamado Loop Case) han sido mal interpretados y han recibido la influencia de las soluciones esgrimidas por Thomson para el caso del tranvía. 
su abuso ha sido la corrupción del pensamiento católico. Yo sugiero que esa corrupción se deriva automáticamente del punto de vista de que un efecto secundario en tanto que tal, por muy seguro que sea y por muy bien que se sepa que lo es [...] tiene menos peso moral que un medio. (Mackie 2000, p. 188).

Otra forma específica de crítica a la DDE sería que la diferencia entre daño instrumental y daño incidental es ilusoria; i.e., una vez que se examinan cuidadosamente los ejemplos paradigmáticos del doble efecto es preciso admitir que los daños incidentales son sólo una forma encubierta de admitir excepciones a la prohibición de daño instrumental. ${ }^{12}$ Ésta es la línea que desarrolla Alison McIntyre en su artículo "Doing Away with Double Effect" (McIntyre 2001, pp. 219255). A pesar de que este artículo ha sido considerado un trabajo "comprensivo, excepcionalmente cuidadoso y finalmente devastador" (Williams 2002, p. 292) para la doctrina del doble efecto, es un tanto decepcionante advertir que los defensores del doble efecto no lo han tomado lo suficientemente en serio. ${ }^{13}$

Al igual que Mackie, McIntyre relativiza la prohibición absoluta del daño instrumental, y en particular asume como un principio obvio y claro la diferencia entre intentar conseguir $R$ como fin de nuestras acciones y solamente prever que $R$ ocurra como consecuencia (McIntyre 2001, p. 226). Sin embargo, para McIntyre el éxito de la doctrina del doble efecto depende de que pueda mostrarse la diferencia y la relevancia moral entre un daño instrumental (intentar $R$ como medio) y un daño incidental (prever que $R$ ocurrirá) (McIntyre

\footnotetext{
${ }^{12}$ Una manera diferente de rescatar el valor de la doctrina del doble efecto consiste no en la defensa de sus distinciones centrales, sino más bien en atribuirle una función diferente. Por ejemplo, Horacio Spector duda de la "verdad moral fundamental", pero distingue diversos ámbitos en los que la doctrina del doble efecto podría tener relevancia. Para este autor la fuerza de la doctrina posee importancia en el nivel de política social. En su opinión:
}

[E]l principal factor de política social a que atiende la distinción intención/previsión es la fuerza motivacional de las prohibiciones morales [...]. Siendo la psicología humana como es, cuando utilizamos medios para lograr ciertos resultados, el foco de nuestra atención está dirigido al factor causal que manipulamos. Es difícil mantener la fuerza motivacional de una prohibición moral si se permite que los agentes morales puedan concentrar su atención en quebrantarla. (Spector 2002, p. 201)

${ }^{13}$ Así, por ejemplo, sorprende que un libro dedicado exclusivamente a esta teoría como el de Thomas A. Cavanaugh (2006) ni siquiera mencione el trabajo de McIntyre. En el libro de Scanlon (2008) tampoco se tiene en cuenta. 
2001, p. 229). Antes de articular una réplica al desafío de McIntyre - y, por la misma razón también a enfoques como el de Mackie - es preciso exponer las líneas generales de su propuesta.

3.1. La relevancia de la distinción entre intentar y prever

McIntyre asume como correcta, obvia y poco controvertida la distinción y la relevancia moral entre quien intenta realizar un daño y quien meramente prevé la consecuencia. Tal como ella lo formula:

No hay nada particularmente controvertido acerca de la pretensión de que es peor desear un daño como fin que provocar el daño como un efecto colateral previsto de promover un buen fin. Y quienes se oponen al DE pueden fácilmente aceptar que hay una prohibición moral general en desear un daño como fin. (McIntyre 2001, p. 226)

Para McIntyre, la DDE se apropia de la fuerza intuitiva de esta obviedad (platitude) y la proyecta sobre el uso de medios dañinos necesarios para obtener un determinado fin. Por esa razón, es tentador suponer que esta doctrina nos da una razón para prohibir el uso de medios dañinos y permitir, en cambio, los males incidentales. Para evitar esta confusión, el doble efecto tiene que justificar "el vínculo entre la incorrección de ciertos casos de daño instrumental con la incorrección de la acción que persigue fines maliciosos" (McIntyre 2001, p. 229). En otras palabras, que el daño instrumental — pero no el daño incidental - está tan prohibido como los fines maliciosos.

McIntyre reconoce que los ejemplos que la doctrina utiliza (bombardero terrorista frente al bombardero estratégico, eutanasia frente a disminución del dolor, etc.) apelan a una intuición poderosa, pero ella argumentará a favor de explicaciones alternativas. Así, incluso si se concede que existe una genuina diferencia moral en los casos contrastados —algo que, por ejemplo, Hart (1973, p. 124) niega-, es posible rechazar la explicación que la DDE hace de los fundamentos para distinguirlos. Aunque es un error negar la relevancia de la distinción entre intentar y prever — como, en su opinión efectivamente ocurre con algunos críticos de la DDE - de allí no se sigue que los partidarios de la distinción también tengan que simpatizar con la DDE. Aunque fuese verdad que esta doctrina está comprometida con esa distinción, no es posible admitir que tal distinción implica a la doctrina. Pasar por alto este dato es lo que explica que quienes rechazan esa doctrina consideran inadmisible aceptar la distinción. A su vez, algo similar ocurre con quien acepta la distinción y luego señala que es imposible rechazar la doctrina del doble efecto (McIntyre 
2001, p. 220). Por tal razón, McIntyre concluye que es beneficioso deshacerse de la DDE pues así se corregirían dos distorsiones en la reconstrucción del razonamiento práctico. En primer lugar, la de los escépticos acerca de la relevancia moral entre resultado intentado y consecuencia prevista (a menudo porque son escépticos acerca de la DDE). En segundo lugar, la de quienes asumen que esa distinción debe ser realizada de modo consistente con la DDE. El primer grupo nunca podrá explicar el valor intuitivo de los ejemplos, y el segundo nunca podrá incorporar nuestros juicios intuitivos acerca de la fuerza de llamar a una consecuencia dañina "meramente prevista" en un enfoque moral complejo, adecuado y coherente (McIntyre 2001, p. 221).

Dicho de otra manera, para McIntyre los ejemplos aducidos por DDE son plausibles en la medida en que efectivamente ilustran el contraste moral entre intención y previsión, pero no sobre la base de la particular distinción, central para la DDE, entre intentar provocar un daño instrumental y provocar un daño incidentalmente como efecto secundario previsto (McIntyre 2001, p. 220).

\subsection{Medios necesarios y consecuencias previstas}

Con el propósito de examinar la mejor versión del doble efecto, McIntyre introduce seis restricciones que, supuestamente, cualquier defensor del doble efecto aceptaría. Estas restricciones tienen por función tanto evitar las debilidades que genera una formulación poco cuidadosa de la doctrina, como impedir sacar provecho de aparentes fortalezas que corresponden a otras intuiciones morales que convergen junto a los principios del doble efecto. Las restricciones que McIntyre desarrolla son las siguientes: 1) para que el daño que se ocasiona esté permitido debe añadirse un principio de proporcionalidad; 2) debe utilizarse el medio menos dañino posible; 3) la DDE sólo se interesa por contrastar situaciones en que se provoca un daño como medio para lograr un fin bueno y en que se prevé un daño como efecto secundario al promover un buen fin; 4) la DDE no implica la relevancia moral entre causar y permitir; 5) para aplicar la doctrina a los casos difíciles, debe haber un criterio de distinción entre aquello que se intenta y lo meramente previsto; 6) si una consecuencia prevista, que no es ni fin ni medio para lograr el fin, no necesita ser atendida por el agente porque no es su responsabilidad, o no debería atenderse porque el agente tiene una razón para mantenerla al margen cuando delibera, en un determinado contexto, entonces, la consecuencia generada es meramente prevista y el agente no deseó 
provocarla. Sin embargo, en estos casos la DDE no explica la permisibilidad de provocar ese daño (McIntyre 2001, pp. 221-242)..$^{14}$

Para McIntyre, la DDE fundamentalmente debe explicar el tratamiento diferente entre daños intentados como medio para lograr un buen fin y daños previstos como efecto secundario de promover un buen fin. Para ella, es obvio que el daño a otro nunca debería ser deseado como fin. La pretensión de que es peor intentar un daño porque uno lo desea como fin que prever un daño que uno lamenta como efecto colateral debe ser calificado como un principio general que acompaña a la DDE pero no la explica ni justifica (McIntyre 2001 , p. 227). Es decir, no hace falta una doctrina especial como la DDE para justificar el reproche a quien intenta provocar un daño como fin de su conducta. De este modo, los ejemplos de la DDE pierden la fuerza intuitiva pues comparan situaciones en que los agentes intentan maliciosamente dañar como fin frente a agentes que actúan de manera benevolente mientras lamentan el efecto dañino colateral. McIntyre compara el caso de un torturador y un dentista que realizan los mismos actos, y causan el mismo dolor. Si se afirma que el acto del dentista está permitido porque se realiza sólo previendo una consecuencia, y el acto del torturador está prohibido porque intenta causar dolor, entonces estos ejemplos no ilustran la DDE, ya que el dentista actúa de manera permitida porque actúa por un buen fin. Aún más, en virtud de ese fin, no sería extraño que el dentista estuviese autorizado a causar ese dolor de manera directa, i.e., intentando causarlo (McIntyre 2001, pp. 227-228).

Una vez que se descarta que la DDE tenga un papel especial en el reproche por los daños que se persiguen como fines, es inevitable interrogarse acerca del alcance de la doctrina, i.e., qué daños reprueba y qué daños admite. La respuesta usual —que McIntyre evalúa críticamente - subraya el daño que se intenta como medio (daño instrumental) para obtener un buen fin. En las versiones tradicionales de la DDE, este daño instrumental se considera prohibido o injustificable, pero McIntyre señala que no hay razón para tratar de manera diferente el daño instrumental y el daño incidental. Si ambos daños fuesen similares, entonces, la DDE debería evaluarlos de la misma manera. Dado que, conforme con la DDE, está permitido, en determinadas circunstancias, causar un mal como consecuencia prevista, entonces ¿cuál es la razón de que este mismo mal no se

${ }^{14}$ Aunque, a diferencia de lo que sostiene McIntyre, un defensor del doble efecto podría discutir la elaboración y el contenido de algunas de las restricciones elaboradas por ella, en este trabajo no me ocuparé de esto. 
pueda intentar como medio para lograr el mismo buen fin? (esta duda también fue planteada por Hart 1973, p. 124). Sin una respuesta a esta pregunta, la DDE enfrentaría un dilema: o bien la doctrina tendría que permitir medios dañinos para buenos fines $o$, por el contrario, tendría que prohibir esos medios malos al igual que el daño incidental. En el primer caso, al igual que las versiones clásicas del consecuencialismo, la doctrina sostendría que la búsqueda de buenos fines justifica el empleo de malos medios y, en el segundo caso, no aportaría específicamente nada relevante a la solución de los problemas prácticos.

En otras palabras: para defender la DDE, es necesario mostrar una diferencia relevante entre el daño instrumental y el daño incidental. Para ello, es usual equiparar "intentar como medio" a "intentar como fin" y, de ese modo, se asume que el intento instrumental comparte todas las características objetables de desear un daño como fin. Pero, si la única justificación para el doble efecto es que es incorrecto provocar un daño como medio porque está mal provocarlo como fin, entonces la DDE presupone lo que hay que probar, i.e., que hay una distinción relevante entre elegir los medios y prever la consecuencia.

Si quienes critican la DDE muestran que se puede provocar el mismo efecto secundario de manera permitida como medio, entonces el DDE no cumple ningún papel. Por consiguiente, los partidarios de DDE no contarían con un argumento independiente frente al que afirma que querer algo como medio es diferente de desearlo como fin (McIntyre 2001, p. 227). ${ }^{15}$

Creo que se podría encontrar una línea de respuesta a críticas como la de Alison McIntyre en la misma estructura del razonamiento práctico y el modo en que filósofos de la acción como von Wright han diferenciado entre medios y consecuencias.

\footnotetext{
${ }^{15}$ McIntyre descarta rápidamente la idea sugerida por Thomas Nagel según la cual una primera estrategia para defender la DDE consiste en examinar la respuesta de los agentes frente al daño que provocan. Para los partidarios del doble efecto, cuando un daño no es intentado sino sólo previsto es normal que los agentes desplieguen determinadas actitudes como culpa, arrepentimiento, etc. De esta manera, si "intentar como medio" es igual a "intentar como fin", entonces esas actitudes estarían ausentes ya que la idea de fin de nuestra conducta típicamente se asocia a lo que deseamos (pretendemos) conseguir. Pero no hay razón para negar que intentar un daño como medio para la realización de un buen fin también es compatible con sentimientos como el lamento, el arrepentimiento, etcétera.
} 
3.3. Un modo de distinguir entre medios necesarios

y consecuencias necesarias previstas

La diferencia entre "intentar como medio" e "intentar como fin" exige reconsiderar el papel que desempeña la intención en la explicación y la justificación de acciones. Los elementos prácticos como "deseo", "voluntad", "motivos" son los que conectan el conocimiento del agente y la explicación de por qué realizó determinado movimiento para conseguir determinado estado de cosas (von Wright 1979b, p. 128; en el mismo sentido Lyons 2005, p. 495). Mediante nuestras acciones generamos una indefinida cantidad de consecuencias causales y ello es así aun cuando no poseamos ningún estado mental al respecto. Si la mera causación de estos efectos generase responsabilidad, entonces seríamos responsables de cualquier efecto de nuestras acciones, ya sea previsto, intentado, imprevisto o incluso fortuito. Sin embargo, ser personalmente responsable implica algo más que ser un elemento en la cadena causal. Un agente es personalmente responsable solamente de acciones deliberadas. En este sentido, al actuar intencionalmente, el agente causa estos estados de cosas porque así lo pretende. Al elegir comprometerse en determinados tipos de conducta o producir un efecto determinado por los propios deseos y creencias -intención-, el actor está conectado de un modo causal único con los estados de cosas que genera.

Por el contrario, la descripción de las creencias de un agente no alcanza para explicar por qué el agente eligió realizar determinada acción, ni por qué ella era inevitable al momento de ejecutarla. Así, el papel de las consecuencias previstas en el razonamiento práctico de un determinado agente es muy diferente del que desempeñan sus intenciones, deseos, voliciones, etc. A diferencia de lo que ocurre cuando intentamos un determinado resultado, la previsión de ciertas consecuencias sugiere que el agente - aunque sea consciente de alguno de los estados de cosas que puede generar- carece de una disposición volitiva afirmativa para con ellas, i.e., no determina su acción. En palabras de Lyons (2005, p. 498):

Porque es precisamente un movimiento cognitivo $y$ volitivo hacia los objetos que capturan la esencia del intentar, no tiene sentido referirse a los efectos meramente previstos como objetos de intención. Los agentes no pueden, por ejemplo, decir que están tratando de lograr esos estados de cosas con respecto a los meros efectos secundarios.

Obviamente todo esto no implica que no seamos responsables de los efectos secundarios que prevemos, sino, más bien, que no 
puede decirse que sean incorrectos porque son intentados. Siempre es verdad que, frente a la misma conducta, el hecho de que ella sea meramente prevista (no intentada) no agrega mayor incorrección al acto que cuando fue realizado con la intención de provocarlo (Finnis 1995, p. 244).

En muchas ocasiones se pretende determinar si un agente es responsable de haber ocasionado un efecto previsto cuando pretendía conseguir un buen fin. Y es justamente en estos casos en los que la DDE adquiere relevancia (Lyons 2005, p. 499). A continuación, sobre la base de las distinciones elaboradas, enfrentaré específicamente el desafío de la diferencia entre daño instrumental y daño incidental.

La elección de cualquier acto como medio para un determinado fin se realiza en función de la capacidad que poseemos para intervenir en el mundo y modificarlo a nuestra voluntad. Los medios son instrumentalmente buenos en la medida en que son útiles para lograr causalmente nuestro fin. ${ }^{16}$ Pero quienes defienden la DDE también reconocen que la relación entre los medios y los fines es compleja. Por eso, uno de los requisitos de la DDE es que los medios sean neutrales o buenos. Es decir, del hecho de que alguien pretenda un buen fin no se sigue que los medios que elija también sean considerados buenos. En palabras de Lyons (2005, p. 501): "Aunque está claro que si un fin es malo se sigue que los medios dirigidos al fin son antiéticos, es un error lógico básico concluir que simplemente porque un fin no es malo, los medios para lograr el fin tampoco lo son."

Ello abre el espacio para revisar la tesis de McIntyre según la cual permitir el daño incidental lleva a permitir el daño instrumental. Según Lyons, el error del argumento de McIntyre radica en que olvida lo maleable y transitorio de lo que constituye un medio o un fin. Lo que en una determinada fase del razonamiento práctico constituye un medio puede ser un fin en sí mismo en otra posterior (Lyons 2005, p. 501). Este punto puede ilustrarse con el ejemplo del bombardero terrorista y el estratégico. Lo que McIntyre plantearía es que si la DDE permite que el bombardero estratégico ocasione las muertes de los civiles como consecuencia de su acción, también tiene que permitir la conducta del bombardero terrorista. En ambos casos, el fin último de ambos pilotos es idéntico: la finalización de la guerra.

\footnotetext{
${ }^{16} \mathrm{El}$ análisis de la noción de medios y sus distintas relaciones, i.e., necesarios, suficientes y contribuyentes, supone un análisis completo acerca de la causalidad. Éste no ha sido el objetivo de mi trabajo, por lo que dejo librado a una noción intuitiva de este concepto. (La bibliografía es inmensa sobre este problema, para un estudio de estas tres nociones véanse, por ejemplo, Spector 1997, pp. 103-106; von Wright 1993, pp. 163-166.)
} 
Pero una vez que los pilotos comienzan a deliberar, ellos poseen distintos modos de alcanzar la victoria como fin. Podría decirse que el bombardero estratégico pretende debilitar al enemigo disminuyendo su capacidad militar, y, a su vez, el bombardero terrorista pretende lograrlo desmoralizando al enemigo al matar civiles. Una vez que eligieron alguna de estas dos alternativas se requieren mayores deliberaciones acerca del modo de lograr cualquiera de ellas como fin. Por ello, para el bombardero terrorista matar civiles se convierte en algo que pretende y, hacerlo, forma parte del razonamiento práctico que guía su plan (Lyons 2005, p. 502). En conclusión, "al actuar así, sin embargo, el agente provoca las muertes de los civiles precisamente de la manera constitutiva afirmativamente volitiva que McIntyre concede que hace al pretender el mal como fin en incorrecto" (Lyons 2005, p. 502; las cursivas son del original).

En principio, los fines que persigue un agente no son fines últimos: constituyen etapas intermedias en una cadena de sucesos y planes de mayor generalidad y abstracción. Por ejemplo, nuestra descripción de ciertos fenómenos con frecuencia adquiere nuevas perspectivas y significados cuando tales fenómenos se insertan en un contexto más amplio de propósitos e interacciones sociales. La invasión de Estados Unidos a Irak en 2003 puede describirse, por ejemplo, como el intento de George W. Bush por defender a su pueblo del "eje del mal", derrocar a un dictador, restaurar la democracia en Medio Oriente, apropiarse de recursos naturales de la zona, etc. (Guibourg 1987, pp. 54-56).

En esta dinámica de medios y fines, la crítica de McIntyre se disuelve ya que — de tener ella razón en la equiparación entre daño instrumental y daño incidental- cualquier daño que el agente provocase se podría describir como un medio permitido para un fin diferente. Para ello, sólo se requiere exigir que la reformulación del "fin perseguido" malo en términos de daño instrumental cumpla con los mismos requisitos que exigimos a la justificación del daño incidental. ${ }^{17}$ Por eso, según Lyons (2005, p. 506):

El hecho de que en abstracto se pueda preferir un "fin" particular o estado de cosas no permite a un agente intentar provocar ese estado de cosas. Una posición contraria ignora el hecho de que lograr ese estado, objetivamente preferido, conlleva actos intencionales específicamente

${ }^{17}$ Esta última condición es importante ya que aun cuando el daño sólo se prevea como una consecuencia incidental (no intentado), la eventual permisión resultante no será una licencia absoluta. sino que exige requisitos adicionales (e.g., proporcionalidad, disposición a compensar, pesadumbre). 
dirigidos a efectos dañinos. Al hacerlo, ignora la intuición de que el deseo volitivo afirmativo de provocar una consecuencia dañina como medio o como fin constituye una elección inmoral o antiética en su forma básica. Basados en la comprensión de la unidad de la culpabilidad personal que surge de las elecciones intencionales de los males como fines o como medios, nada problemático surge del reclamo del doble efecto de que el daño previsto puede causarse algunas veces de modo permitido aunque no intentado.

Al reconstruir el argumento de McIntyre, vimos que para ella hay una diferencia moral genuina entre intentar una acción disvaliosa como fin y prever ese mismo daño como consecuencia. Sin embargo, para McIntyre esta distinción (en ninguno de los diversos significados que posee) recoge aquello que la doctrina del doble efecto debe mostrar. Esa teoría necesita dar cuenta de que es peor ocasionar un daño instrumentalmente que prever ese mismo daño como cuestión incidental. Sin embargo, la relación entre medios y fines es más compleja de lo que parece sugerir McIntyre. En particular, que el fin pretendido por el agente no sea malo no abre juicio acerca de la naturaleza moral de los medios empleados. En la elección de los medios, el agente interviene de manera decisiva, se compromete con un curso de acción específico y, por ello, cuando el medio es malo, su intención también es defectuosa. Por el contrario, esas actitudes no se transmiten necesariamente al daño incidental.

\section{Dolo indirecto y doctrina del doble efecto}

He intentado mostrar que la diferencia entre daño instrumental y daño incidental debe tener relevancia en la atribución de responsabilidad, ya que nuestros compromisos prácticos son diferentes en ambos casos. Para mostrar cómo funciona esta distinción he utilizado la doctrina del doble efecto y en esta sección pretendo esbozar de qué manera los principios de esa doctrina impactan en la atribución de responsabilidad a título de dolo indirecto. No pretendo ofrecer un análisis general; más bien utilizaré el caso Thomas como ejemplo de un argumento en favor de revisar el alcance del dolo indirecto.

El objeto de intención de Thomas era cobrar el seguro, y hacer estallar el tonel con dinamita era una condición necesaria para lograr ese fin. Para él, detonar el explosivo constituía una necesidad práctica, i.e., la única manera de satisfacer sus deseos a la luz de sus creencias. (Utilizo estos términos en el sentido en que los usa Wright; véase, por ejemplo, von Wright 1993). Esta conexión es la que parece 
tener en mente von Wright cuando expone la idea de lo que se necesita en sentido práctico (practical necessitation). Su ejemplo es el siguiente:

Un hombre va caminando hacia la estación de tren. Él quiere estar allí a tiempo para cuando llegue el tren. Quizás está esperando a que llegue su novia. Mira su reloj y se da cuenta de que el tren arribará en unos pocos minutos y que, si continúa caminando tranquilamente, llegará tarde. No hay taxis a la vista. Tiene que correr, y se pone en movimiento. (Von Wright 1993, p. 168)

En este ejemplo, la ausencia de otros medios de transporte impone la necesidad de correr para llegar a tiempo a la estación. Si hubiese taxis a la vista, el agente no tendría que echar a correr. El contexto determina aquello que se necesita, al menos en el sentido en que si hubiese otro medio de llegar a tiempo a la estación, entonces no habríamos explicado por qué el agente echó a correr. En la "lógica" de esta situación, el agente forma su intención incluyendo en su compromiso práctico los medios necesarios. Por esa razón, cuando ellos son disvaliosos podemos reprocharlos a título de dolo, ya que su "voluntad de conseguir el fin" es, en ese contexto, inseparable de los medios necesarios.

En el razonamiento práctico del agente, su intención de conseguir un determinado resultado y sus creencias acerca de los medios necesarios para lograrlo son necesariamente razones para su acción. Esas razones y la acción del agente están internamente conectadas y su presencia determina la acción del agente. En otras palabras, frente a una oportunidad de actuar (es decir, si el agente no padece incapacidades, si dispone de la habilidad necesaria para llevar adelante sus propósitos, etc.), el agente actúa ("se pone en movimiento", "se dirige a su fin"). El análisis de ese razonamiento práctico aparentemente permite distinguir en el complejo epistémico volitivo dos "intenciones": la actitud práctica hacia el fin y hacia el medio. Sin embargo, esta distinción en el plano analítico no debe llevarnos a pensar que se trata de dos cosas "numéricamente" diferentes. Nuestra intención de conseguir un determinado fin está conceptualmente conectada a nuestra determinación de emplear los medios necesarios para lograrlo. Por supuesto, al momento de formar su intención, el agente puede advertir lo gravoso de las consecuencias de su conducta y abandonar su plan, pero, en tanto mantenga su intención, necesita también mantener su actitud práctica sobre los medios necesarios. Si 
el agente pierde su disposición a emplear el medio necesario, entonces la premisa práctica que guía el razonamiento se disuelve, i.e., el agente ya no ve en el estado de cosas querido un fin de su acción (un objeto de intención).

La valoración del fin como algo bueno (deseado, querido) se muestra, en última instancia, en la valoración de los medios como algo bueno (deseado, querido). En este sentido, la distinción entre bondad instrumental y bondad intrínseca es sólo un artefacto analítico. Consideremos el siguiente esquema de razonamiento práctico, propuesto por Spector:

(1) F es intrínsecamente bueno

(2) $M$ contribuye causalmente a $F$

(3) $M$ es instrumentalmente bueno

Aunque las proposiciones (1) y (3) parecen expresar diferentes valoraciones, la distinción sólo se produce en el plano del análisis. En este sentido, Spector señala:

La expresión "bueno instrumentalmente" no hace referencia a una segunda valoración. Cuando el agente que hace el razonamiento dice " $M$ es bueno instrumentalmente" tan sólo transmite en forma abreviada el contenido de las premisas (1) y (2); no hace una valoración diferente de la expresada en la primera premisa. La llamada valoración instrumental es en realidad una "sombra conceptual" proyectada por la valoración intrínseca [...]. (Spector 1997, p. 107)

En esa conexión radica la fuerza intuitiva del denominado "Principio de la Transmisión de la Voluntad". Kant creía que este principio era de naturaleza analítica y por ello afirmaba:

El que quiere el fin quiere también (en tanto que la razón tiene influjo decisivo sobre sus acciones) el medio indispensable necesario para alcanzarlo, si está en su poder. Esta proposición es, en lo que respecta al querer, analítica: pues en el querer un objeto como efecto mío está pensada ya mi causalidad como causa activa, es decir, el uso de los medios, y el imperativo saca ya el concepto de las acciones necesarias para tal fin del concepto de un querer ese fin. (Kant 1983, p. 37)

Luego, continúa de la siguiente forma: 
[U]na vez que sé que sólo mediante esa acción puede producirse el citado efecto, si quiero íntegro el efecto, quiero también la acción que es necesaria para él, y esto último sí que es una proposición analítica, pues es lo mismo representarme algo como efecto posible de cierta manera por mí y representarme a mí mismo como obrando de esa manera con respecto a tal efecto. (Kant 1983, p. 37)

La naturaleza analítica del principio de la transmisión de la voluntad exige reconstruir la intención del agente como un fenómeno complejo, pero inseparable. ${ }^{18}$ Conforme a esta reconstrucción, la atribución de responsabilidad se justifica de manera similar al modo en que se reprocha el dolo directo, es decir, por la intención del agente de provocar un daño ya sea como fin o como medio.

Ahora bien, ¿qué responsabilidad cabe atribuir frente a los medios suficientes (productivos)? Para responder a esta pregunta es preciso destacar que la explicación de una acción particular en términos de condiciones suficientes es insatisfactoria ya que no da una respuesta completa a la interrogante de por qué el agente se comporta de cierta manera. Supongamos que el agente que desea llegar a tiempo a la estación tiene a su disposición un taxi, pero echa a correr en lugar de utilizar esa opción. Frente a esta circunstancia ya no podemos sostener que el agente tenía necesariamente que echar a correr para llegar a la estación a tiempo. Ese objeto de intención (i.e., su deseo) no impone la conducta que el agente despliega y, por eso, no conocemos exactamente por qué el agente ha actuado de esa manera. $\mathrm{Su}$ intención, por así decirlo, posee un margen de indeterminación. Sólo una mayor especificación de la situación podrá ayudarnos a identificar el alcance de la intención del agente y nos dará la clave de una explicación completa de su conducta. Por ejemplo, podría ocurrir que el agente no tuviese dinero para pagar el taxi y, entonces, en ese contexto su única opción era comenzar a correr. Este margen de indeterminación también repercute sobre nuestra atribución de responsabilidad y, en la medida en que no sabemos qué hace el agente (i.e., qué lo mueve a actuar de la manera en que se comporta), habría un salto injustificado en la atribución de responsabilidad por dolo. De este modo, una doctrina como la DDE, o alguna semejante que otorgue relevancia a la distinción entre intentar y prever, no niega que se pueda imputar dolo en casos de medios suficientes. Más bien lo que señala es que la explicación de la acción aún se encuentra

${ }^{18}$ En este texto asumo que este principio reconstruye correctamente las intenciones del agente. Sin embargo, la fundamentación de ese principio exige una revisión general del razonamiento práctico, algo que excede los límites de este trabajo. 
incompleta y que debemos postergar una respuesta concluyente hasta reunir la información que sirva para dar cuenta de qué ha determinado la acción del agente.

En resumen: si entendemos el dolo indirecto del modo que abarque la elección que un agente hace de los medios para lograr su fin no habrá diferencias significativas entre las propuestas de la dogmática y las que elabora la DDE (o alguna otra doctrina que admita la relevancia de la distinción entre intentar y prever). En virtud del principio de la transmisión de la voluntad -i.e., quien desea el fin también desea los medios para conseguirlo-, las conductas abarcadas por el dolo indirecto formarían parte de aquello que el agente pretende hacer y en este sentido merece el mismo reproche.

\section{Conclusiones}

Una de las ideas centrales de este trabajo ha sido insistir en la utilidad de retomar la discusión sobre medios necesarios y consecuencias necesarias en el derecho penal, en particular, para el análisis del dolo indirecto. Una consecuencia importante de esta discusión es que, en gran medida, la figura del dolo indirecto queda vacía de contenido. Ello es así porque o bien algunas situaciones (intentar algo como medio) se fundamentan del mismo modo que el reproche a título de dolo directo, o bien es injustificado responsabilizar como dolosas aquellas consecuencias meramente previstas.

La estrategia argumental que he desarrollado está basada en algunas de las principales intuiciones de la doctrina del doble efecto. $\mathrm{He}$ señalado que esa doctrina necesita responder al desafío de la diferencia entre daño instrumental y daño incidental. He intentado mostrar cómo puede darse una respuesta plausible a este desafío mostrando la diferencia de compromiso práctico que hay entre quien pretende algo dañino como medio y quien prevé que esa misma consecuencia ocurrirá. De esta manera, podemos distinguir entre aquellos estados de cosas que el agente intenta (como medios o como fines) y aquellas consecuencias previstas. La diferencia entre el daño instrumental y el daño incidental radica en que el primero es intentado, mientras que el segundo es meramente previsto. Este argumento deja la polémica acerca del doble efecto en un territorio bien conocido: la relevancia moral de la distinción entre intentar y prever. Con independencia de la necesidad de dar una respuesta adecuada a este desafío clásico, es importante destacar que ese problema es diferente del problema de mostrar que "intentar algo como medio" comparte propiedades centrales con "intentar algo como fin". 
Al utilizar los conceptos de medios necesarios y consecuencias necesarias en el derecho penal damos cuenta, en una gran parte de los casos, de manera más intuitiva de que aquello que estamos reprochando se conecta con aquello que el agente intenta hacer. Por supuesto, las consecuencias de aquellas cosas que intentamos hacer quedarán fuera de este grado de imputación. Ello no quiere decir que no se deban reprochar, ni siquiera que no debamos reprocharlas de forma grave. Sólo indica que el reproche no se asienta en las mismas bases, y por lo tanto deberíamos entenderlo como figura separada. ${ }^{19,20}$

\section{BIBLIOGRAFÍA}

Cavanaugh, T., 2006, Double Effect Reasoning. Doing Good and Avoiding Evil, Oxford University Press, Oxford.

Finnis, J., 1995, "Intention in Tort Law", en D. Owen (comp.), Philosophical Foundations of Tort Law, Oxford University Press, Oxford (Clarendon Paperbacks), pp. 229-247.

González Lagier, D., 2001, Las paradojas de la acción, Publicaciones Universidad de Alicante, Alicante.

Guibourg, R., 1987, El fenómeno normativo, Astrea, Buenos Aires.

Hart, H.L.A., 1973, "Intention and Punishment", Punishment and Responsibility, Clarendon Press, Oxford, pp. 113-135.

Jescheck, H., 1993, Tratado de Derecho Penal. Parte General, Comares, Granada.

Kant, I., 1983, Fundamentación de la metafísica de las costumbres, Porrúa, México.

Lyons, E., 2005, "In Incognito - The Principle of Double Effect in American Constitutional Law", Florida Law Review, vol. 57, no. 3, pp. 469-563.

Mackie, J.L. 2000, Ética. La invención de lo bueno y lo malo, Gedisa, Barcelona.

Manrique, L., 2007, "Responsabilidad, dolo eventual y doble efecto", Doxa, vol. 30, pp. 415-434.

${ }^{19}$ Ello muestra que las categorías conceptuales creadas por la dogmática penal continental, i.e., dolo e imprudencia, son insuficientes para dar respuesta a las variaciones de diferentes grados de intencionalidad. En este sentido, sería conveniente revisar la utilidad de incorporar al análisis dogmático categorías como las utilizadas por el derecho penal anglosajón: propósito, conocimiento, recklessness (desconsideración), negligencia. Al respecto, véase Ragués 2008, p. 176.

${ }^{20}$ Agradezco a dos dictaminadores anónimos y a los participantes del Seminario de Investigadores del Instituto de Investigaciones Filosóficas (UNAM), donde tuve la oportunidad de discutir este trabajo. Sus comentarios, críticas y sugerencias me ayudaron a evitar errores y mejorar este artículo. 
McIntyre, A., 2001, "Doing Away with Double Effect”, Ethics, vol. 111, no. 2, pp. 219-255.

Núñez, R., 1965, Tratado de Derecho Penal, Lerner, Córdoba (Argentina).

Otsuka, M., 2008, "Double Effect, Triple Effect and Trolley Problem:

Squaring the Circle in Looping Cases", Utilitas, vol. 20, no. 1, pp. 92 110.

Ragués, R., 2008, La ignorancia deliberada en derecho penal, Atelier, Barcelona.

- 1 1999, El dolo y su prueba en el proceso penal, Bosch, Barcelona.

Roxin, C., 1997, Derecho Penal. Parte General, Civitas, Madrid.

Sancinetti, M., 2005, Teoría del delito y disvalor de acción, Hammurabi, Buenos Aires.

Scanlon, T., 2008, Moral Dimensions. Permissibility, Meaning, Blame, Harvard University Press, Cambridge, Mass./Londres.

Spector, H., 2002, "Suicidio médicamente asistido y autonomía", en O. Hansberg, y M. Platts (comps.), Responsabilidad y libertad, Instituto de Investigaciones Filosóficas-UNAM/Fondo de Cultura Económica, México, pp. 181-203.

— , 1997, “La doctrina del doble efecto ¿Ética o religión?”, Perspectivas Bioéticas, vol. 2, no. 1, pp. 93-110.

Von Wright, G., 1993, The Varieties of Goodness, Thoemmes Press, Bristol.

Cornell University Press, Nueva York, pp. 100-129.

——, 1979a, Norma y acción. Una investigación lógica, Tecnos, Madrid.

——, 1979b, Explicación y comprensión, Alianza Universidad, Madrid.

Williams, B., 2002, Truth and Truthfulness. An Essay in Genealogy, Princeton University Press, Princeton/Oxford.

Zaffaroni, E., A. Alagia, y A. Slokar, 2002, Derecho Penal: Parte General, Ediar, Buenos Aires.

Recibido el 12 de mayo de 2011; revisado el 16 de noviembre de 2011; aceptado el 8 de febrero de 2012. 